\title{
1 Enhancement of lycopene bioaccessibility 2 from tomato juice using excipient emulsions: 3 Influence of lipid droplet size
}

\section{Salvia-Trujillo, L.; McClements, D.J."}

Department of Food Science, University of Massachusetts, Amherst, MA, 01003

\begin{abstract}
Journal: Food Chemistry
\end{abstract}
Submitted: January 2016

Revised: April 2016

*Department of Food Science, University of Massachusetts, Amherst, MA, 01003; Fax 413545 1262; Tel 413545 1019; email: mcclements@foodsci.umass.edu. 


\section{Abstract}

18 The use of excipient emulsions to increase the bioaccessibility of lycopene in tomato

19 juice was studied by simulating gastrointestinal conditions. The influence of droplet diameter $20(d=0.17$ or $19 \mu \mathrm{m})$ and thermal treatment $\left(90^{\circ} \mathrm{C}, 10 \mathrm{~min}\right)$ on lycopene bioaccessibility was 21 evaluated. Lycopene bioaccessibility was relatively low $(<8 \%)$ in the absence of excipient 22 emulsions due to the crystalline nature of the carotenoids and their entrapment within 23 chromoplasts. Emulsions containing small droplets were fully digested within the small 24 intestine phase, and led to a higher bioaccessibility (12.5\%) than emulsions containing large 25 droplets $(10.0 \%)$ or emulsion-free samples $(7.5 \%)$. The relatively modest increase in 26 bioaccessibility was attributed to the high level of entrapment in crystalline form. Thermal 27 processing did not appreciably disrupt tomato cells, and therefore only led to a slight increase 28 in lycopene bioaccessibility. Overall, this study shows that excipient emulsions may increase 29 the bioaccessibility of carotenoids in tomato juices. 30

Keywords: tomato; lycopene; nanoemulsion; excipient foods; bioaccessibility; lipid 32 digestibility 


\section{Introduction}

Lycopene is a carotenoid that is responsible for the deep red color of fresh tomato fruit and tomato-based products (Shi \& Maguer, 2000). Like other carotenoids, lycopene is a highly hydrophobic molecule with a long hydrocarbon structure containing many conjugated double bonds. Despite not having pro vitamin A activity, lycopene has been proposed to be responsible for several other health benefits associated with the intake of tomato products (Stahl \& Sies, 1996). Lycopene functions as an antioxidant and its ability to quench singlet oxygen has been reported to be twice as high as $\beta$-carotene (Shi \& Maguer, 2000). The consumption of lycopene-rich products has been suggested to provide protection against cardiovascular diseases and a broad range of cancers (Etminan, Takkouche, \& CaamanoIsorna, 2004). Lycopene represents $90 \%$ of the total carotenoid compounds in tomato fruit (Borguini \& Torres, 2009). Thus, the consumption of tomato-based food products represents a major source of lycopene in the human diet. In plant tissues, carotenoids are typically located in chromoplasts inside the plant cells. Chromoplasts are specific organelles composed of lipids, proteins, and carotenoids that can have several different morphologies in plant tissues, such as crystalline, globular, fibrillar, membranous or tubular (Bartley \& Scolnik, 1995). The nature of the chromoplasts in different plant tissues may influence their release within the gastrointestinal tract after ingestion, which would be expected to influence carotenoid bioaccessibility.

Lycopene bioaccessibility, which is usually taken to be the fraction incorporated into mixed micelles formed in the small intestine, is typically quite low in raw tomato products, ranging between about 0.1 and $3 \%$ (Reboul, Richelle, Perrot, Desmoulins-Malezet, Pirisi, \& Borel, 2006). This is a consequence of the lipophilic nature of carotenoids, their high melting point, and their entrapment in complex structures within tomato tissue. In fact, carotenoids have to be released from the food matrix after ingestion and be incorporated in the micelle fraction before becoming absorbable in the gastrointestinal tract. Therefore, the tomato tissue microstructure plays an important role in determining the bioaccessibility of lycopene in tomato products. However, there are also other factors that influence lycopene bioavailability in tomato products. Food processing often has a positive impact on carotenoid bioavailability due to its ability to disrupt plant tissue structure. The application of thermal treatment to tomato products might weaken the cell wall structure thus facilitating the diffusion and release of carotenoids from chromoplasts and therefore increasing their bioaccessibility 
66 (Tibäck, Svelander, Colle, Altskär, Alminger, Hendrickx, et al., 2009). The presence of digestible lipids has also been shown to increase the in vitro bioaccessibility of carotenoids in plant-based products (I. J. P. Colle, Van Buggenhout, Lemmens, Van Loey, \& Hendrickx, 2012). This effect can be attributed to the fact that the digestion of lipids within the gastrointestinal tract releases free fatty acids and monoacylglycerols that increase the solubilization capacity of mixed micelles thereby enhancing carotenoid solubilization. Therefore, the application of thermal processing in the presence of digestible lipids might be an effective strategy to enhance the bioactive properties of tomato products.

Recently, the concept of excipient foods has been introduced: these are foods that contain ingredients or structures that may not have bioactivity themselves, but that can promote the bioactivity of co-ingested bioactive agents by increasing their bioavailability (David Julian McClements \& Xiao, 2014). Oil-in-water emulsions or nanoemulsions are particularly suitable candidates as excipient foods because their structure and composition can easily be manipulated. In particular, they can be designed to contain hydrophobic, hydrophilic, and amphiphilic ingredients that may promote bioavailability of different bioactive agents through different mechanisms. In this study, we focused on the utilization of nanoemulsions to increase the bioaccessibility of carotenoids from plant based-products. Nanoemulsions, consisting of lipid droplets $(d<100 \mathrm{~nm})$ dispersed within an aqueous phase have several potential advantages over conventional emulsions for this purpose. Firstly, they tend to have a higher stability to gravitational separation and droplet aggregation, which may lead to a longer shelf-life (D. J. McClements \& Rao, 2011). Second, the small size of the lipid droplets means that they may be able to more easily penetrate into plant tissues and solubilize carotenoids. Third, small droplets tend to be digested more rapidly within the gastrointestinal tract due to their large surface areas, which tends to promote the bioaccessibility of any encapsulated bioactive compounds (Salvia-Trujillo, Qian, Martín-Belloso, \& McClements, 2013). Therefore, nanoemulsions might be a potential excipient food to be co-ingested with food products in order to enhance the bioavailability of naturally occurring bioactive compounds. However, the effectiveness of excipient nanoemulsions at increasing the bioavailability of specific bioactive compounds from specific food products still needs to be elucidated. In this context, the purpose of the present work was to study the influence of the 
juice. These emulsion-based systems were designed to represent commercial products that could be mixed with tomato juices, such as sauces or creams.

The results of this study may be useful for developing a new range of excipient food products specifically designed to boost the bioavailability of health-promoting bioactive components in fresh and processed fruits and vegetables.

\section{Material and methods}

\subsection{Materials}

Corn oil purchased from a local supermarket was used as a source of digestible long chain triacylglycerols (LCT). Tomato juice was obtained from a local supermarket (Foodhold USA, LLC, Landover, MD, USA). The manufacturer claimed on the label that the tomato juice did not contain fat ( $0 \%$ oil content). The initial concentration of lycopene in the tomato juice was determined to be $8.6 \pm 0.3 \mathrm{mg} / 100 \mathrm{~g}$ juice. Tween 80 , monobasic and dibasic phosphates, pepsin, bile salts and lipase were purchased from Sigma-Aldrich (St. Louis, MO). The lipase used was purified lipase from porcine pancreas (type II) and the bile salts used were porcine bile extract. Acetone, hexane and ethanol for the lycopene extraction were purchased from Fischer (Pittsburgh, PA, USA). All aqueous solutions were prepared using purified water from a Milli-Q filtration system (EMD Millipore, Merck KGaA, Darmstadt, Germany).

\subsection{Methods}

\subsubsection{Emulsion and nanoemulsion formation}

The oil phase consisted of pure corn oil and the aqueous phase consisted of a $5 \mathrm{mM}$ phosphate buffer at $\mathrm{pH}$ 7. Conventional emulsions, also referred to as large emulsions (LE), were obtained by blending $10 \%(\mathrm{w} / \mathrm{w})$ of the oil phase (corn oil), $1 \%(\mathrm{w} / \mathrm{w}$ ) of Tween 80 , and $89 \%(\mathrm{w} / \mathrm{w})$ of aqueous phase using a high-shear mixer at 20,000 rpm for $2 \mathrm{~min}$. Nanoemulsions, also referred to as small emulsions (SE), were formed by passing the conventional emulsions three times through a high pressure homogenizer (Microfluidizer, Model M110-P, Microfluidics, Newton, MA) working at 20,000 psi. 


\subsubsection{Mixing and heat experiments}

To simulate co-ingestion of tomato juice with an emulsion-based excipient food we mixed the two systems together prior to passing through the simulated gastrointestinal tract. Tomato juice $(24 \mathrm{~mL})$ and emulsion ( $6 \mathrm{~mL}$ LE or SE) were mixed together to achieve an oil concentration of $2 \%(\mathrm{w} / \mathrm{w})$ in the final samples. A control sample containing no added lipids was also prepared by mixing $24 \mathrm{~mL}$ tomato juice and $6 \mathrm{~mL}$ buffer solution $(5 \mathrm{mM}$ phosphate buffer, $\mathrm{pH}$ 7). The resulting mixtures were then stirred for 5 minutes. Moreover, to study the effect of thermal processing on the functionality of tomato juice, we submerged the mixed tomato-emulsion samples in a hot water bath at $90^{\circ} \mathrm{C}$ for 10 minutes followed by an icedwater bath for 10 minutes. After mixing and thermal treatment, the tomato juice samples were subjected to in vitro gastrointestinal conditions.

\subsubsection{In vitro digestion}

An in vitro gastrointestinal tract (GIT) model consisting of mouth, stomach and small intestinal phases was used to simulate the gastrointestinal fate of ingested tomato juice samples. The parameters selected for the simulation of gastrointestinal conditions were based on previously reported recommendations (Minekus, Alminger, Alvito, Ballance, Bohn, Bourlieu, et al., 2014). Initially, the tomato juice-emulsion mixtures had $2 \%$ (w/w) oil content.

Mouth phase: Simulated saliva fluid (SSF), containing mucin and various salts, was prepared according to a previous study (Sarkar, Goh, \& Singh, 2009). A $10 \mathrm{~mL}$-aliquot of the test samples was mixed with $10 \mathrm{~mL}$ of SSF, so that the final mixture contained $1 \%(\mathrm{w} / \mathrm{w})$ oil. The $\mathrm{pH}$ of the mixture was adjusted to 6.8 and the sample was incubated at $37^{\circ} \mathrm{C}$ for $10 \mathrm{~min}$ with continuous agitation at $100 \mathrm{rpm}$.

Gastric phase: Simulated gastric fluid (SGF) was prepared using a method reported previously (Sarkar, Goh, Singh, \& Singh, 2009) by dissolving $2 \mathrm{~g}$ of $\mathrm{NaCl}$ and $7 \mathrm{~mL}$ of $\mathrm{HCl}$ (37\%) in $1 \mathrm{~L}$ of water and adjusting the $\mathrm{pH}$ to 1.2 using $1.0 \mathrm{M} \mathrm{HCl}$. The "bolus" sample from the mouth phase was mixed with SGF at a 50:50 volume ratio so that the final mixture contained $0.5 \%(\mathrm{w} / \mathrm{w})$ oil. The $\mathrm{pH}$ of the sample was adjusted to $2.5 \mathrm{using} \mathrm{NaOH}(1 \mathrm{M})$ and incubated at $37^{\circ} \mathrm{C}$ for 2 hours with continuous agitation at $100 \mathrm{rpm}$.

Small intestinal phase: A pH-stat (Metrohm, 147 USA Inc.) was used to simulate the conditions in the small intestinal phase of the GIT. An aliquot $(30 \mathrm{~mL})$ of sample from the gastric phase was placed in a temperature-controlled $\left(37^{\circ} \mathrm{C}\right)$ chamber and the $\mathrm{pH}$ was set at 

chloride $(110 \mathrm{mg} / \mathrm{mL})$ solutions dissolved in phosphate buffer were added to the sample and the $\mathrm{pH}$ was adjusted to 7.0 if necessary. Afterwards, $2.5 \mathrm{~mL}$ of freshly prepared lipase suspension $(24 \mathrm{mg} / \mathrm{mL})$ dissolved in phosphate buffer was incorporated into the mixture. The $\mathrm{pH}$ of the mixture was monitored and the volume of $0.1 \mathrm{M} \mathrm{NaOH}(\mathrm{mL})$ necessary to neutralize the free fatty acids (FFA) released from the lipid digestion (i.e., to keep $\mathrm{pH}$ at 7.0) was recorded during $2 \mathrm{~h}$. The amount of FFA released was calculated from the titration curves as described previously (Li \& McClements, 2010).

It should be noted that the relatively simple static in vitro GIT model used in this study cannot simulate the complex conditions that occur within the human gastrointestinal tract, such as dynamic changes in $\mathrm{pH}$, bile salt levels, enzyme levels, etc. Nevertheless, this method is useful for rapidly screening samples with different compositions and structures, which can then be tested in more detail using in vivo methods.

\subsubsection{Particle characteristics}

The physicochemical properties of the tomato juice with and without being mixed with small or large emulsion were determined in terms of the particle size, particle distribution and $\zeta$-potential immediately after being mixed and in each phase during the simulated gastrointestinal conditions.

The mean particle size and particle size distribution of tomato juice samples were measured with a laser diffraction particle size analyzer (LS 13 320, Beckman Coulter Inc., USA) equipped with a universal liquid module. The instrument consists of a $5 \mathrm{~mW}$ laser diode with a wavelength of $750 \mathrm{~nm}$ and a secondary tungsten-halogen light source projected

178 through a set of filters, which transmit three wavelengths $(450 \mathrm{~nm}, 600 \mathrm{~nm}$, and $900 \mathrm{~nm})$, to measure particles that fall in the submicron range. The tomato juice samples were suspended in the liquid module in double distilled water prior to the particle size measurement to avoid multiple scattering effects. The particle size was reported as volume-weighted mean diameter 182 in $\mu \mathrm{m}$.

183 The $\zeta$-potential of the particles was measured by phase-analysis light scattering (Zetasizer

184 NanoZS, Malvern Instruments, Worcestershire, UK). Samples were diluted 1:10 with $5 \mathrm{mM}$ 185 phosphate buffer solution ( $\mathrm{pH}$ 7.0) and then placed in a capillary cell equipped with two 186 electrodes to assess the electrophoretic mobility of the particles. 


\subsubsection{Lycopene bioaccessibility}

To determine the lycopene bioaccessibility (BA) in tomato samples, the fraction of solubilized lycopene in the micelle phase after the simulated gastrointestinal tract versus the concentration after the small intestine phase was reported. An aliquot of the raw digesta after the small intestine phase was centrifuged (CL10 centrifuge, Thermo Scientific) at $2600 \times \mathrm{g}$ for $40 \mathrm{~min}$ at $25{ }^{\circ} \mathrm{C}$. The supernatant was collected and was taken to be the "micelle fraction" in which the lycopene was solubilized.

The lycopene concentration in the initial tomato juice, digested tomato samples, and the micelle fraction was determined by a method reported previously (Fish, Perkins-Veazie, \& Collins, 2002) with some modifications. Briefly, an aliquot of $0.3 \mathrm{~g}$ of the tomato sample was mixed with $2.5 \mathrm{~mL}$ of acetone containing a $0.05 \%$ (w/v) of butylated hydroxytoluene (BHT), with $2.5 \mathrm{~mL}$ of ethanol and $5 \mathrm{~mL}$ of hexane in a $15 \mathrm{~mL}$ test tube with a plastic screw cap. The test tubes were vortexed for $10 \mathrm{sec}$ twice and then further centrifuged at $320 \mathrm{~g}$ for $15 \mathrm{~min}$.

Then, $3 \mathrm{~mL}$ of double distilled water was added and left for $5 \mathrm{~min}$ at room temperature to allow phase separation to occur. The upper organic layer was collected and analyzed spectrophotometrically (Ultrospec 3000 pro, GE Health Sciences, USA) at $503 \mathrm{~nm}$. A blank cuvette containing pure hexane was used as a reference cell. The concentration of lycopene in each sample was determined with the following equation:

$$
\text { lycopene }(m g / 100 g)=\frac{A b s 503 \times M W \times \text { Vol hexane } \times 100}{\varepsilon \times L \times g \text { tomato }}
$$

where $A b s_{503}$ is the absorbance of the organic layer at $503 \mathrm{~nm} ; M W$ is the lycopene molecular weight $(536.9 \mathrm{~g} / \mathrm{mol})$; Vol hexane is the volume of hexane used $(5 \mathrm{~mL}) ; \varepsilon$ is the lycopene extinction coefficient $\left(17.2 \times 10^{4}(\mathrm{M} / \mathrm{cm})^{-1}\right) ; L$ is the cuvette path length $(1 \mathrm{~cm})$ and $g$ tomato is the sample weight $(0.3 \mathrm{~g})$.

The lycopene bioaccessibility was calculated using the following equation:

$$
\text { Bioaccessibility }=\frac{C_{\text {micelle }}}{C_{\text {RawDigesta }}} \times 100
$$

where $\mathrm{C}_{\text {micelle }}$ and $\mathrm{C}_{\text {RawDigesta }}$ are the concentrations of lycopene in the micelle fraction and in the overall sample (raw digesta) after the in vitro digestion, respectively. In this study, we did not take into account the transformation (chemical or biochemical) or absorption of the lycopene, which would also be expected to contribute to the overall bioavailability. 


\subsubsection{Tomato juice microstructure}

215 The tomato juice microstructure was determined by microscopy. The overall appearance 216 of tomato cells was observed by optical microscopy, whereas to detect the location of the 217 carotenoids in the tomato chromoplasts confocal fluorescence microscopy was used.

218 Carotenoids naturally fluoresce and so it is possible to detect their location in these organelles 219 (D'Andrea, Amenos, \& Rodriguez-Concepcion, 2014; Kilcrease, Collins, Richins, Timlin, \& 220 O'Connell, 2013). Moreover, by the same principle, it is possible to track the possible 221 migration of carotenoids from the tomato chromoplasts to the oil droplets after mixing with 222 the emulsions. For the optical microscopy images, a Nikon Microscope (Nikon D-Eclipse C1 223 80i, Nikon, Melville, NY) was used with a 20× objective lens. A small aliquot of each sample 224 was placed on a microscope slide and covered with a cover slip prior to analysis. For confocal 225 microscopy images, an air-cooled argon ion laser Model IMA1010 BOS (Melles Griot, 226 Carlsbad, CA) was used to excite Nile red at $488 \mathrm{~nm}$. The resulting fluorescent spectra of 227 carotenoids were detected in the $515 \mathrm{~nm}$ channel equipped with a narrow pass filter (HQ $228515 / 30 \mathrm{~m}$ ) with a pinhole size of $150 \mu \mathrm{m}$. The images generated had a size of $512 \times 512$ 229 pixels, with a pixel size of $414 \mathrm{~nm}$, and a pixel dwell time of $61.44 \mu \mathrm{s}$. All images were taken 230 and processed using the instrument software program (EZ- CS1 version 3.8, Nikon, Melville, $231 \mathrm{NY})$.

\subsubsection{Statistical analysis}

Experiments were carried out in duplicate, and the results were expressed as the mean and the standard deviation. A statistical analysis software program (JMP 8, SAS Institute Inc.) was used to perform the analysis of variance. The Student's t test was run to determine

236 significant differences at a 5\% significance level $(\mathrm{p}<0.05)$.

\section{Results and discussion}

\subsection{Particle size and particle size distribution}

In this section we studied the particle size of tomato juice samples during in vitro

240 digestion and the influence of adding excipient large or small emulsions, with oil droplet sizes 241 of $19.0 \pm 0.1 \mu \mathrm{m}$ and $0.167 \pm 0.001 \mu \mathrm{m}$, respectively. Moreover we assessed the impact of the 242 application of a heat treatment $\left(90^{\circ} \mathrm{C}\right.$ for $\left.10 \mathrm{~min}\right)$ on the particle size of tomato juice to mimic 243 a cooking process. The initial mean particle diameter of the raw tomato juice was around 390 
$\mu \mathrm{m}$ and it remained practically unchanged during passage through the mouth, stomach, and small intestine phases (Figure 1 A). This observation was supported by the particle size distributions, which showed a population of large particles around $400 \mu \mathrm{m}$ that remained present throughout in vitro digestion (Figure 2). Typically, tomato-derived products can be considered to be suspensions of plant-tissue-based particles in an aqueous phase that contains dissolved pectin, sugars, and organic acids (Anthon, Diaz, \& Barrett, 2008). The plant-based particles consist of mechanically disrupted parenchyma tissue, which are cells in spherical or polyhedral shape, with a diameter of 50 to $500 \mu \mathrm{m}$ and are held together by the pectin of the middle lamella (Aguilera \& Stanley, 1990). The particle size of vegetable purees or juices largely depends on the mechanical treatment applied and it will vary according to the presence of cell clusters or cell fragments (Katlijn R. N. Moelants, Cardinaels, Jolie, Verrijssen, Van Buggenhout, Zumalacarregui, et al., 2013). Our results are in agreement with other studies reporting that tomato juice or tomato puree products have mean particle diameters between about 350 to $700 \mu \mathrm{m}$ (K. R. N. Moelants, Cardinaels, Van Buggenhout, Van Loey, Moldenaers, \& Hendrickx, 2014). Nevertheless, there is little information regarding the influence of the passage of foods through the different gastrointestinal phases on their particle size. In agreement with our results, it has been reported that the structure of carrot tissues remained unaffected after in vitro digestion with intact carotene bodies remaining within the interior of the plant cells (Tydeman, Parker, Wickham, Rich, Faulks, Gidley, et al., 2010).

We did not detect a significant change in the mean particle diameter or particle size distribution of tomato juice after adding large or small excipient emulsions (Figure 1), which can be attributed to the fact that large particles scatter light much more intensity than smaller ones, and therefore dominate the overall light scattering signal. Thus, the oil droplets remain undetected when they are mixed with tomato juice containing much larger particles. Applying a heat treatment $\left(90^{\circ} \mathrm{C}, 10 \mathrm{~min}\right)$ to the tomato juice (with or without excipient emulsions) did not have a significant impact on the measured particle size, which suggests that the plant tissue remained intact. Conversely, other authors have reported that applying heat to plantbased products might induce cell wall softening and structural changes causing a particle size reduction (Lemmens, Van Buggenhout, Oey, Van Loey, \& Hendrickx, 2009). However, morphology changes of plant-based suspensions induced by thermal treatment largely depend 
Jolie, Verrijssen, Van Buggenhout, Van Loey, et al., 2014). Other authors have also reported that thermal degradation of pectin in the cell wall and middle lamella weakens the intercellular adhesion leading to cell separation rather than cell rupture (Ormerod, Ralfs, Jackson, Milne, \& Gidley, 2004). On the other hand, we observed a slight increase in particle size of tomato juice in the small intestine phase after adding a small emulsion with or without the application of heat, presenting values near $500 \mu \mathrm{m}$. This increase in particle size may be an indication of some loosening of the plant tissue structure in the presence of lipid digestion products. For example, free fatty acids or monoacylglycerols may penetrate into the plant tissue and increase the gaps between the cells. Alternatively, the observed increase in particle size may be due to the formation of complexes of plant tissues and mixed micelles.

\section{$3.2 \zeta$-potential}

The $\zeta$-potential of initial raw tomato juice (T) was around -35 mV (Figure 1 B). The negative charge of the tomato juice samples observed in the present work might be attributed to the presence soluble anionic polysaccharides (such as pectin) at the surfaces of the planttissue particles or dissolved within the aqueous phase. Mechanical homogenization processing to obtain the juice induces the solubilization of structural compounds of the plant cell wall such as pectin. Pectin consists of a group of polymers with linear regions of $\alpha(1-4)$ linked galacturonic acid units separated by branched regions of neutral sugars (Sila, Van Buggenhout, Duvetter, Fraeye, De Roeck, Van Loey, et al., 2009). A fraction of the galacturonic acid groups are esterified with methyl groups, thus the overall molecular charge depends on the ratio of esterified to nonesterified groups, as well as the $\mathrm{pH}$ relative to the $\mathrm{pK}_{\mathrm{a}}$ of the acid groups $\left(\mathrm{pK}_{\mathrm{a}} \approx 3.5\right)$. Thus, pectin molecules tend to be negatively charged at high $\mathrm{pH}$, but lose their charge at pH values appreciably below pH 3.5 (Espinal-Ruiz, ParadaAlfonso, Restrepo-Sanchez, Narvaez-Cuenca, \& McClements, 2014). Other authors have also reported a negative charge (-26 mV) for carrot juice (Chen, Zhao, Yang, \& Zhang, 2012).

After adding excipient small or large emulsions the $\zeta$-potential of the tomato juice samples became less negative (-24 and $-25 \mathrm{mV})$, respectively. This change in particle charge might be due to a contribution of the lipid droplets to the overall signal, or due to an interaction of the anionic particles or polymers in the tomato juice with the lipid droplets.

The $\zeta$-potential of tomato juice with or without excipient emulsions remained negative in the mouth and stomach phases (Figure 1 B), with values between -24 and $-26 \mathrm{mV}$. The 
aqueous phase used to dilute these samples was phosphate buffer $(\mathrm{pH} 7)$. Nevertheless, when we measured the $\zeta$-potential of the same samples using simulated saliva fluid for the mouth ( $\mathrm{pH}$ 6.8) or simulated stomach fluid for the stomach $(\mathrm{pH} 2.5)$ as dispersants, the $\zeta$-potential was -21.5 and $+0.64 \mathrm{mV}$ respectively. These differences in $\zeta$-potential depending on dispersant type can be attributed to the different $\mathrm{pH}$, which significantly impacts the electrical charge of anionic polysaccharides (such as pectin). A pronounced increase in the magnitude of the negative charge was observed after exposure to simulated small intestine conditions, which was more pronounced in the tomato juice samples containing large or small excipient emulsions compared to tomato juice. The digestion of triglycerides by pancreatic lipase results in the release of anionic free fatty acids (Singh, Ye, \& Horne, 2009), which might alter the overall charge of the suspended food particles. On the other hand, heat-treated $\left(90{ }^{\circ} \mathrm{C} 10\right.$ min) tomato juice containing small or large excipient emulsions presented a significantly more negative $\zeta$-potential after the small intestine phase compared to the non-treated juice (Figure 1 B). The lower $\zeta$-potential observed in heat-treated samples might be due to several reasons: (i) thermal treatments disrupt the cell membrane allowing pectin and ions in the cell to migrate to the external aqueous phase (K. R. N. Moelants, Cardinaels, Van Buggenhout, Van Loey, Moldenaers, \& Hendrickx, 2014); and (ii) pectin present in the cell wall might be degraded due to $\beta$-elimination processes or acid hydrolysis induced by thermal processing thereby altering its charge characteristics (Greve, McArdle, Gohlke, \& Labavitch, 1994).

\subsection{Oil digestibility}

The FFA release in the small intestine phase of the samples largely depended on the type of excipient emulsion added and also on the application of a thermal treatment $\left(90^{\circ} \mathrm{C}, 10\right.$ min) after mixing with the excipient emulsions (Figure 3). As expected, tomato juice and heat-treated tomato juice without excipient emulsions did not show a significant release of FFA since they did not contain oil, as indicated by the manufacturer. On the other hand, tomato juice containing the small excipient emulsion exhibited rapid lipid digestion: $85 \%$ of the FFAs were released after $10 \mathrm{~min}$, and complete lipid digestion had occurred after 2 hours. However, the tomato juice containing the large excipient emulsion exhibited much slower lipid digestibility: only $40 \%$ FFAs were released after $10 \mathrm{~min}$ and only $85 \%$ FFAs has been released after 2 hours. The differences between the rate of lipid digestion in small and large excipient emulsions can be attributed to differences in their initial droplet size. The small emulsion had an initial mean droplet diameter around $0.17 \mu \mathrm{m}$, whereas the large emulsion 
340 had one around $19 \mu \mathrm{m}$. Emulsions with smaller droplet sizes are digested faster than those 341 with larger droplet sizes due to the higher active surface area of lipid exposed to digestive 342 enzymes (Salvia-Trujillo, Qian, Martín-Belloso, \& McClements, 2013). Moreover, the fact 343 that the small or large emulsions were mixed with a tomato juice did appear to interfere with 344 their digestibility. On the other hand, the tomato juice containing excipient emulsions that 345 were thermally treated $\left(90^{\circ} \mathrm{C} 10 \mathrm{~min}\right)$ had a lower FFA release compared to the 346 corresponding non-thermally treated samples. For example, the heat-treated tomato juice containing the small excipient emulsion only released $50 \%$ FFAs after 10 min of in vitro digestion and only reached $80 \%$ FFAs release after 2 hours. This could be possibly due to the destabilization of the oil droplets during the heat treatment, which led to an increase in the oil droplet size and therefore a decrease in the surface area available for the lipase to adsorb. In fact, we detected a significant increase in the oil droplet size after heat treatment in the optical microscope images as described in the following section (Figure 5 B). Other authors have reported droplet growth in nanoemulsions stabilized with non-ionic surfactants (Tween 80) after being exposed to temperatures above $70^{\circ} \mathrm{C}$ and then cooled to ambient temperature (Saberi, Fang, \& McClements, 2013). Droplet instability was mainly attributed to an increase in droplet coalescence as the temperature was increased, associated with dehydration of the non-ionic surfactant head-group leading to a reduction in phase inversion temperature. The thermal stability of emulsion-based delivery systems mixed with food products is of particular importance as they are often exposed to elevated temperatures during preservation operations.

\subsection{Tomato juice microstructure}

Changes in the microstructure of the tomato juice samples during passage through the simulated gastrointestinal tract were studied by optical and confocal microscopy. Raw tomato juice was observed to contain both whole and disrupted chromoplasts suspended in an aqueous serum phase (Figure 4 A). These chromoplasts appeared to contain crystalline carotenoid granules entrapped inside the cell membrane. It is known that carotenoids found in vegetable tissues have complex structures that depend on tissue type. Moreover, throughout the gastrointestinal phases, the structure of the chromoplasts appeared to stay unchanged and the carotenoid granules remained in the interior of the tomato tissue cells. After adding large or small excipient emulsions the oil droplets remained outside the chromoplasts and were not able to penetrate into the interior of the tomato cells (Figure $4 \mathbf{A}$ ). In the case of tomato juice 
chromoplasts in the mouth and stomach phases and some oil droplets were detected in the small intestine phase, which can be attributed to the fact that not all of the oil phase was digested for this sample (see previous section). For the tomato juice mixed with the small excipient emulsion, the oil droplets were undetectable throughout the in vitro digestion phases since their droplet size was below the limit of resolution of the microscope used.

The microstructure of the thermally-treated tomato juice (with or without excipient emulsions) was monitored by confocal microscopy (Figure 4 B). Confocal images showed the presence of carotenoid (lycopene) granules in the interior of the chromoplasts, which appeared as red spots since carotenoids naturally fluoresce. We did not detect any noticeable tomato cell breakage by the action of thermal processing. Moreover, there appeared to be no increase in tomato cell permeability, since the lycopene globules remained in the interior of the tomato cells in the mouth and stomach phases. Nevertheless, the carotenoid bodies appeared partially disrupted in the small intestine phase, and the undigested oil droplets (LE) were seen to be loaded with lycopene (Figure 4 B). The microscopy images therefore support the results of the $\mathrm{pH}$-stat in vitro digestion experiments, where some undigested oil was detected in a number of the tomato samples: T+LE, T+SE+Heat, and T+LE+Heat (Figure 3). Additionally, we compared optical and confocal images of the tomato juice samples after mixing with excipient emulsions and being heat-treated (Figure 5). Initially, the oil droplets did not have any fluorescence after the thermal treatment, whereas they did fluoresce after the small intestine phase. This indicates that the lycopene was not transferred into the lipid droplets after simple mixing of the tomato juice with the excipient emulsions, nor after thermal processing. Nevertheless, the undigested oil after the small intestine phase was loaded with lycopene, which suggested that passage of the samples through the simulated gastrointestinal tract did facilitate the transfer of lycopene into the lipid droplets. This phenomenon may have occurred because the mixed micelles formed by lipid digestion facilitated the disruption of the lycopene-containing structures within the plant cells, and were also capable of solubilizing them.

Different carotenoid-containing structures have been found in vegetable products, including plastoglobules, crystalline and microfibrillar structures, and internal membranous structures (Egea, Bian, Barsan, Jauneau, Pech, Latche, et al., 2011). In tomatoes, carotenoids are found as solid crystalline substructures inside the chromoplasts (Jeffery, Holzenburg, \& King, 2012). The chromoplasts structure, as well as the cell wall composition and 
404

405

406

407

408

409

410

411

412

413

414

415

416

417

418

419

420

421

422

423

424

425

426

427

428

429

430

431

432

433

434

435

organization of the specific plant tissue, may therefore have a major impact on the release of carotenoids in the gastrointestinal tract. In our study, the crystalloid globular structure of carotenoids in tomato chromoplasts may account for the relatively low bioaccessibility of lycopene observed in raw tomato juice (7.5\%) after in vitro digestion. It has been reported that the bioaccessibility of lycopene is much lower from tomatoes than from carrots (Palmero, Lemmens, Ribas-Agusti, Sosa, Met, Umutoni, et al., 2013). Even though the carotenoids in both vegetables had similar solid crystalline morphologies, they attributed the lower lycopene bioaccessibility in tomato to differences in the chromoplast sub-organization as well as other plant matrix effects that might decrease the release of the carotenoids into the mixed micelle phase.

\subsection{Lycopene BA}

We assessed the lycopene bioaccessibility from tomato juice after exposure of the samples to the simulated gastrointestinal conditions before and after being mixed with small or large excipient emulsions and with or without heat-treatment $\left(90^{\circ} \mathrm{C} 10 \mathrm{~min}\right.$ ) (Figure 6).

The lowest lycopene bioaccessibility was observed in the raw tomato juice without containing any excipient emulsion, which was $7.5 \%$. Mixing an excipient emulsion with the tomato juice significantly increased the lycopene bioaccessibility with the effect being greater for the emulsion with the smallest droplets: $\mathrm{BA}=10.1 \%$ for large droplets and $12.5 \%$ for small droplets. This effect can be attributed to the higher lipid digestibility for the small excipient emulsions mixed with the tomato juice (Figure 3), as this would lead to more mixed micelles to solubilize the carotenoids. Other studies have also reported that the addition of a lipid source to plant-based products will increase the bioaccessibility of lipophilic compounds due to the presence of a higher amount of mixed micelles (Periago, Bravo, García-Alonso, \& Rincón, 2013). However, the increase in lycopene bioaccessibility from tomato products has been reported to vary depending on the type and concentration of oil added (I. J. P. Colle, Van Buggenhout, Lemmens, Van Loey, \& Hendrickx, 2012). Conversely, it has been reported that the addition of high concentrations of digestible lipids (e.g. olive oil, sunflower oil and fish oil) might decrease the lycopene bioaccessibility in tomato products due to an incomplete hydrolysis of the triglycerides (Anese, Bot, Panozzo, Mirolo, \& Lippe, 2015). It has also been reported that adding an oil-in-water emulsion might lead to a lower increase in lycopene bioaccessibility from tomato products compared to adding a bulk oil if the emulsifier 
interferes with the transfer of lycopene into the lipid droplets or mixed micelles (Degrou, Georgé, Renard, \& Page, 2013).

Overall, our results suggest that the addition of a digestible lipid source in the form of an excipient emulsion only causes a limited increase in lycopene bioaccessibility after digestion of tomato products, which is probably due to the high level of entrapment of the carotenoids in the tissue cells. Lycopene is a highly lipophilic molecule which, in order to be isolated from the matrix, has to be transferred first from the innermost physical barrier (chromoplast), across the cell wall and through the aqueous environment surrounding the cells, which might be considered an additional physical barrier for carotenoid incorporation into the oil phase (Palmero, et al., 2013). The embedment of chromoplasts in complex structures within the tomato tissue cells makes it difficult to be released within the gastrointestinal tract, therefore remaining entrapped after digestion, thus being difficult to enhance its bioaccessibility.

It is generally assumed that thermally treated plant-based products have a higher carotenoid bioaccessibility due to an increase in the cell wall permeability and therefore an easier release of lipophilic compounds during digestion (Netzel, Netzel, Zabaras, Lundin, Day, Addepalli, et al., 2011). Our results indicate that a thermal treatment ( $90^{\circ} \mathrm{C} 10 \mathrm{~min}$ ) of tomato juice only led to a small but significant increase in lycopene bioaccessibility after in vitro digestion compared to raw tomato juice (Figure 6). However, there were no significant differences between the heat-treated tomato juices mixed with small or large excipient emulsions compared to the respective raw tomato juices mixed with excipient emulsions. Nonetheless, the thermally treated tomato juice mixed with a small excipient emulsion showed the highest values of lycopene BA after in vitro digestion (13.8\%). This result suggests that heat treatment may enhance the release of lycopene in tomato products, but it has a minimal effect when combined with the presence of excipient emulsions. Other authors have reported that the addition of lipid prior to processing might enhance carotenoid bioaccessibility in vegetables (I. Colle, Van Buggenhout, Van Loey, \& Hendrickx, 2010). Nevertheless, the type of carotenoid seems to play a crucial role in this aspect. There is evidence indicating that the application of heat after mixing with lipids might even decrease lycopene bioaccessibility of tomato products (Ines J. P. Colle, Lemmens, Van Buggenhout, Met, Van Loey, \& Hendrickx, 2013). Thermal processing might lead to the solubilization of pectin, therefore creating a polysaccharide network within the gastrointestinal fluids that entraps the carotenoids and limits their incorporation into the mixed micelles. Our initial 
468

469

470

471

472

473

474

475

476

477

478

479

480

481

482

483

484

485

486

487

488

489

490

theory was that nanoemulsions with a small droplet size would be more effective in enhancing the tomato lycopene BA compared with larger droplet size excipient emulsions. Nevertheless, our results indicate that the high level of entrapment of the lycopene-rich particles inside chromoplasts inhibits their transfer to the lipid phase during gastrointestinal conditions. Nonetheless, the lycopene BA was enhanced to a higher extent by mixing it with a small emulsion prior to a heat treatment.

\section{Conclusions}

The current work showed that excipient emulsions containing small digestible lipid droplets $(d<200 \mathrm{~nm})$ can increase the bioaccessibility of lycopene from tomato products.

Small excipient emulsions mixed with tomato juice were completely digested under simulated gastrointestinal conditions, which facilitates the transfer of lycopene into the mixed micelles in the small intestine phase. Nevertheless, the lycopene bioaccessibility of tomato juice samples was limited by the strong level of natural entrapment within the chromoplasts, which remained intact during the in vitro digestion, thus preventing the lycopene transfer into the lipid droplets. Moreover the lycopene in tomato is present in a crystalloid form, which impedes its liberation and solubilization within the aqueous phase. The application of a thermal treatment after mixing of the excipient emulsions with the tomato juice, simulating a cooking process, did not lead to a significant increase in the lycopene bioaccessibility. These results suggest that fact that lycopene is trapped within the chromoplasts of tomato products is a major obstacle limiting the release and subsequent incorporation of lycopene within the micelle fraction after digestion. Overall, this study has provided valuable information for the rational design of excipient foods to be co-ingested with fruit- or vegetable-based food products to enhance their potential health benefits.

\section{Acknowledgements}

492 This material is based upon work supported by the Cooperative State Research, 493 Extension, Education Service, United State Department of Agriculture, Massachusetts 494 Agricultural Experiment Station (Project No. 831) and by the United States Department of 495 Agriculture, NRI Grants (2011-03539, 2013-03795, and 2014-67021). 
Aguilera, J. M., \& Stanley, D. W. (1990). Microstructural principles of food processing \& engineering. London; New York; New York, NY, USA: Elsevier Applied Science ; Sole distributor in the USA and Canada, Elsevier Science Pub. Co.

Anese, M., Bot, F., Panozzo, A., Mirolo, G., \& Lippe, G. (2015). Effect of ultrasound treatment, oil addition and storage time on lycopene stability and in vitro bioaccessibility of tomato pulp. Food Chemistry, 172(0), 685-691.

Anthon, G. E., Diaz, J. V., \& Barrett, D. M. (2008). Changes in pectins and product consistency during the concentration of tomato juice to paste. Journal of Agricultural and Food Chemistry, 56(16), 7100-7105.

Bartley, G. E., \& Scolnik, P. A. (1995). Plant carotenoids - Pigments for photoprotection, visual attraction, and human health. Plant Cell, 7(7), 1027-1038.

Borguini, R. G., \& Torres, E. (2009). Tomatoes and Tomato Products as Dietary Sources of Antioxidants. Food Reviews International, 25(4), 313-325.

Chen, C., Zhao, W., Yang, R. J., \& Zhang, S. (2012). Effects of pulsed electric field on colloidal properties and storage stability of carrot juice. International Journal of Food Science and Technology, 47(10), 2079-2085.

Colle, I., Van Buggenhout, S., Van Loey, A., \& Hendrickx, M. (2010). High pressure homogenization followed by thermal processing of tomato pulp: Influence on microstructure and lycopene in vitro bioaccessibility. Food Research International, 43(8), 2193-2200.

Colle, I. J. P., Lemmens, L., Van Buggenhout, S., Met, K., Van Loey, A. M., \& Hendrickx, M. E. (2013). Processing tomato pulp in the presence of lipids: The impact on lycopene bioaccessibility. Food Research International, 51(1), 32-38.

Colle, I. J. P., Van Buggenhout, S., Lemmens, L., Van Loey, A. M., \& Hendrickx, M. E. (2012). The type and quantity of lipids present during digestion influence the in vitro bioaccessibility of lycopene from raw tomato pulp. Food Research International, 45(1), 250-255.

D'Andrea, L., Amenos, M., \& Rodriguez-Concepcion, M. (2014). Confocal Laser Scanning Microscopy Detection of Chlorophylls and Carotenoids in Chloroplasts and Chromoplasts of Tomato Fruit. In M. RodriguezConcepcion (Ed.), Plant Isoprenoids: Methods and Protocols, vol. 1153 (pp. 227-232).

Degrou, A., Georgé, S., Renard, C. M. G. C., \& Page, D. (2013). Physicochemical parameters that influence carotenoids bioaccessibility from a tomato juice. Food Chemistry, 136(2), 435-441.

Egea, I., Bian, W. P., Barsan, C., Jauneau, A., Pech, J. C., Latche, A., Li, Z. G., \& Chervin, C. (2011). Chloroplast to chromoplast transition in tomato fruit: spectral confocal microscopy analyses of carotenoids and chlorophylls in isolated plastids and timelapse recording on intact live tissue. Ann Bot, 108(2), 291-297.

Espinal-Ruiz, M., Parada-Alfonso, F., Restrepo-Sanchez, L. P., Narvaez-Cuenca, C. E., \& McClements, D. J. (2014). Impact of dietary fibers methyl cellulose, chitosan, and pectin on digestion of lipids under simulated gastrointestinal conditions. Food \& Function, 5(12), 3083-3095.

Etminan, M., Takkouche, B., \& Caamano-Isorna, F. (2004). The role of tomato products and lycopene in the prevention of prostate cancer: A meta-analysis of observational studies. Cancer Epidemiology Biomarkers \& Prevention, 13(3), 340-345. 
Fish, W. W., Perkins-Veazie, P., \& Collins, J. K. (2002). A quantitative assay for lycopene that utilizes reduced volumes of organic solvents. Journal of Food Composition and Analysis, 15(3), 309-317.

Greve, L. C., McArdle, R. N., Gohlke, J. R., \& Labavitch, J. M. (1994). Impact of heating on carrot firmness - changes in cell-wall components. Journal of Agricultural and Food Chemistry, 42(12), 2900-2906.

Jeffery, J., Holzenburg, A., \& King, S. (2012). Physical barriers to carotenoid bioaccessibility. Ultrastructure survey of chromoplast and cell wall morphology in nine carotenoid-containing fruits and vegetables. Journal of the Science of Food and Agriculture, 92(13), 2594-2602.

Kilcrease, J., Collins, A. M., Richins, R. D., Timlin, J. A., \& O'Connell, M. A. (2013). Multiple microscopic approaches demonstrate linkage between chromoplast architecture and carotenoid composition in diverse Capsicum annuum fruit. Plant Journal, 76(6), 1074-1083.

Lemmens, L., Van Buggenhout, S., Oey, I., Van Loey, A., \& Hendrickx, M. (2009). Towards a better understanding of the relationship between the beta-carotene in vitro bioaccessibility and pectin structural changes: A case study on carrots. Food Research International, 42(9), 1323-1330.

Li, Y., \& McClements, D. J. (2010). New Mathematical Model for Interpreting pH-Stat Digestion Profiles: Impact of Lipid Droplet Characteristics on in Vitro Digestibility. Journal of Agricultural and Food Chemistry, 58(13), 8085-8092.

McClements, D. J., \& Rao, J. (2011). Food-Grade Nanoemulsions: Formulation, Fabrication, Properties, Performance, Biological Fate, and Potential Toxicity. Critical Reviews in Food Science and Nutrition, 51(4), 285-330.

McClements, D. J., \& Xiao, H. (2014). Excipient foods: designing food matrices that improve the oral bioavailability of pharmaceuticals and nutraceuticals. Food \& Function, 5(7), 1320-1333.

Minekus, M., Alminger, M., Alvito, P., Ballance, S., Bohn, T., Bourlieu, C., Carriere, F., Boutrou, R., Corredig, M., Dupont, D., Dufour, C., Egger, L., Golding, M., Karakaya, S., Kirkhus, B., Le Feunteun, S., Lesmes, U., Macierzanka, A., Mackie, A., Marze, S., McClements, D. J., Menard, O., Recio, I., Santos, C. N., Singh, R. P., Vegarud, G. E., Wickham, M. S. J., Weitschies, W., \& Brodkorb, A. (2014). A standardised static in vitro digestion method suitable for food - an international consensus. Food \& Function, 5(6), 1113-1124.

Moelants, K. R. N., Cardinaels, R., Jolie, R. P., Verrijssen, T. A. J., Van Buggenhout, S., Van Loey, A. M., Moldenaers, P., \& Hendrickx, M. E. (2014). Rheology of Concentrated Tomato-Derived Suspensions: Effects of Particle Characteristics. Food and Bioprocess Technology, 7(1), 248-264.

Moelants, K. R. N., Cardinaels, R., Jolie, R. P., Verrijssen, T. A. J., Van Buggenhout, S., Zumalacarregui, L. M., Van Loey, A. M., Moldenaers, P., \& Hendrickx, M. E. (2013). Relation Between Particle Properties and Rheological Characteristics of Carrotderived Suspensions. Food and Bioprocess Technology, 6(5), 1127-1143.

Moelants, K. R. N., Cardinaels, R., Van Buggenhout, S., Van Loey, A. M., Moldenaers, P., \& Hendrickx, M. E. (2014). A Review on the Relationships between Processing, Food Structure, and Rheological Properties of Plant-Tissue-Based Food Suspensions. Comprehensive Reviews in Food Science and Food Safety, 13(3), 241-260.

Netzel, M., Netzel, G., Zabaras, D., Lundin, L., Day, L., Addepalli, R., Osborne, S. A., \& Seymour, R. (2011). Release and absorption of carotenes from processed carrots 
(Daucus carota) using in vitro digestion coupled with a Caco-2 cell trans-well culture model. Food Research International, 44(4), 868-874.

Ormerod, A. P., Ralfs, J. D., Jackson, R., Milne, J., \& Gidley, M. J. (2004). The influence of tissue porosity on the material properties of model plant tissues. Journal of Materials Science, 39(2), 529-538.

Palmero, P., Lemmens, L., Ribas-Agusti, A., Sosa, C., Met, K., Umutoni, J. D., Hendrickx, M., \& Van Loey, A. (2013). Novel targeted approach to better understand how natural structural barriers govern carotenoid in vitro bioaccessibility in vegetable-based systems. Food Chemistry, 141(3), 2036-2043.

Periago, M. J., Bravo, S., García-Alonso, F. J., \& Rincón, F. (2013). Detection of Key Factors Affecting Lycopene in Vitro Accessibility. Journal of Agricultural and Food Chemistry, 61(16), 3859-3867.

Reboul, E., Richelle, M., Perrot, E., Desmoulins-Malezet, C., Pirisi, V., \& Borel, P. (2006). Bioaccessibility of carotenoids and vitamin E from their main dietary sources. Journal of Agricultural and Food Chemistry, 54(23), 8749-8755.

Saberi, A. H., Fang, Y., \& McClements, D. J. (2013). Effect of glycerol on formation, stability, and properties of vitamin-E enriched nanoemulsions produced using spontaneous emulsification. Journal of Colloid and Interface Science, 411, 105-113.

Salvia-Trujillo, L., Qian, C., Martín-Belloso, O., \& McClements, D. J. (2013). Influence of particle size on lipid digestion and $\beta$-carotene bioaccessibility in emulsions and nanoemulsions. Food Chemistry, 141(2), 1472-1480.

Sarkar, A., Goh, K. K. T., \& Singh, H. (2009). Colloidal stability and interactions of milkprotein-stabilized emulsions in an artificial saliva. Food Hydrocolloids, 23(5), 12701278.

Sarkar, A., Goh, K. K. T., Singh, R. P., \& Singh, H. (2009). Behaviour of an oil-in-water emulsion stabilized by beta-lactoglobulin in an in vitro gastric model. Food Hydrocolloids, 23(6), 1563-1569.

Shi, J., \& Maguer, M. L. (2000). Lycopene in Tomatoes: Chemical and Physical Properties Affected by Food Processing. Critical Reviews in Food Science and Nutrition, 40(1), $1-42$.

Sila, D. N., Van Buggenhout, S., Duvetter, T., Fraeye, I., De Roeck, A., Van Loey, A., \& Hendrickx, M. (2009). Pectins in Processed Fruit and Vegetables: Part II - StructureFunction Relationships. Comprehensive Reviews in Food Science and Food Safety, 8(2), 86-104.

Singh, H., Ye, A., \& Horne, D. (2009). Structuring food emulsions in the gastrointestinal tract to modify lipid digestion. Progress in Lipid Research, 48(2), 92-100.

Stahl, W., \& Sies, H. (1996). Lycopene: A Biologically Important Carotenoid for Humans? Archives of Biochemistry and Biophysics, 336(1), 1-9.

Tibäck, E. A., Svelander, C. A., Colle, I. J. P., Altskär, A. I., Alminger, M. A. G., Hendrickx, M. E. G., Ahrné, L. M., \& Langton, M. I. B. C. (2009). Mechanical and Thermal Pretreatments of Crushed Tomatoes: Effects on Consistency and In Vitro Accessibility of Lycopene. Journal of Food Science, 74(7), E386-E395.

Tydeman, E. A., Parker, M. L., Wickham, M. S. J., Rich, G. T., Faulks, R. M., Gidley, M. J., Fillery-Travis, A., \& Waldron, K. W. (2010). Effect of Carrot (Daucus carota) Microstructure on Carotene Bioaccessibilty in the Upper Gastrointestinal Tract. 1. In Vitro Simulations of Carrot Digestion. Journal of Agricultural and Food Chemistry, 58(17), 9847-9854. 


\section{Figure captions}

Figure 1 Volume-weighted mean particle size $(\mu \mathrm{m})(\mathrm{A})$ and $\zeta$-potential $(\mathrm{mV})(\mathrm{B})$ of tomato juice $(\mathrm{T})$ mixed with a large emulsion $(\mathrm{T}+\mathrm{LE})$ or a small emulsion $(\mathrm{T}+\mathrm{SE})$ and after the application of heat $\left(90^{\circ} \mathrm{C} 10 \mathrm{~min}\right)(\mathrm{T}+\mathrm{H}, \mathrm{T}+\mathrm{LE}+\mathrm{H}, \mathrm{T}+\mathrm{SE}+\mathrm{H})$ during the in vitro digestion. Different capital letters represent significant differences $(p<0.05)$ between in vitro digestion phases for the same sample. Different lower case letters represent significant differences $(p<$ 0.05 ) between different samples in a given in vitro digestion phase (initial, mouth, stomach or small intestine)

Figure 2 Particle size distribution of raw tomato juice $(\mathrm{T})$ during the in vitro digestion phases (initial, mouth, stomach and small intetsine)

Figure 3. Calculated free fatty acids released (\%) from the tomato juice (T) containing small (SE) or large (LE) excipient emulsions with or without applying heat $\left(90^{\circ} \mathrm{C}\right.$ for $10 \mathrm{~min}$ ) over time during the course of the in vitro small intestine stage.

Figure 4 Optical images $(20 \mathrm{X})$ of tomato juice $(\mathrm{T})$, tomato juice with large (T+LE) or small $(\mathrm{T}+\mathrm{SE})$ excipient emulsion (A) and confocal images $(60 \mathrm{X})$ of heated samples $\left(90{ }^{\circ} \mathrm{C} 10 \mathrm{~min}\right)$ of tomato juice (T+Heat), tomato juice with large emulsion ( $\mathrm{T}+\mathrm{LE}+\mathrm{Heat})$ and tomato juice with small emulsion (T+SE+Heat) (B) under simulated gastrointestinal conditions. Scale bar is $100 \mu \mathrm{m}(\mathrm{A})$ and $50 \mu \mathrm{m}(\mathrm{B})$

Figure 5 Comparison of optical and confocal images (60X) of tomato juice with large (A) $(\mathrm{T}+\mathrm{LE}+\mathrm{Heat})$ or small (B) $(\mathrm{T}+\mathrm{SE}+\mathrm{Heat})$ emulsion immediately after heat treatment $\left(90^{\circ} \mathrm{C} 10\right.$ min) and after in vitro small intestine phase. Scale bar is $50 \mu \mathrm{m}$.

Figure 6 Lycopene bioaccessibility (BA; \%) of tomato juice (T) mixed with large (LE) or small (SE) excipient emulsions with or without a posterior heat treatment $\left(90^{\circ} \mathrm{C} 10 \mathrm{~min}\right)$. 


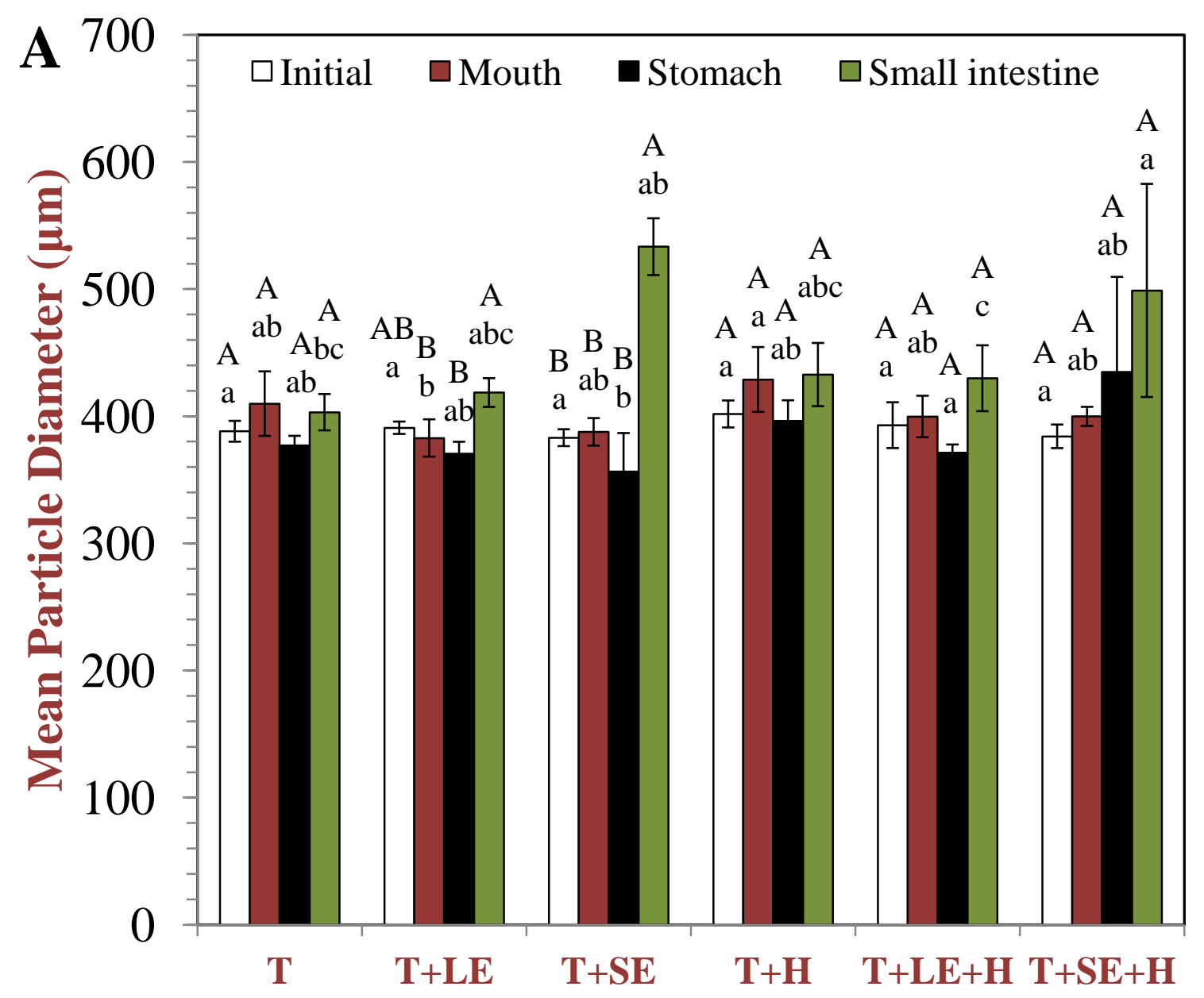




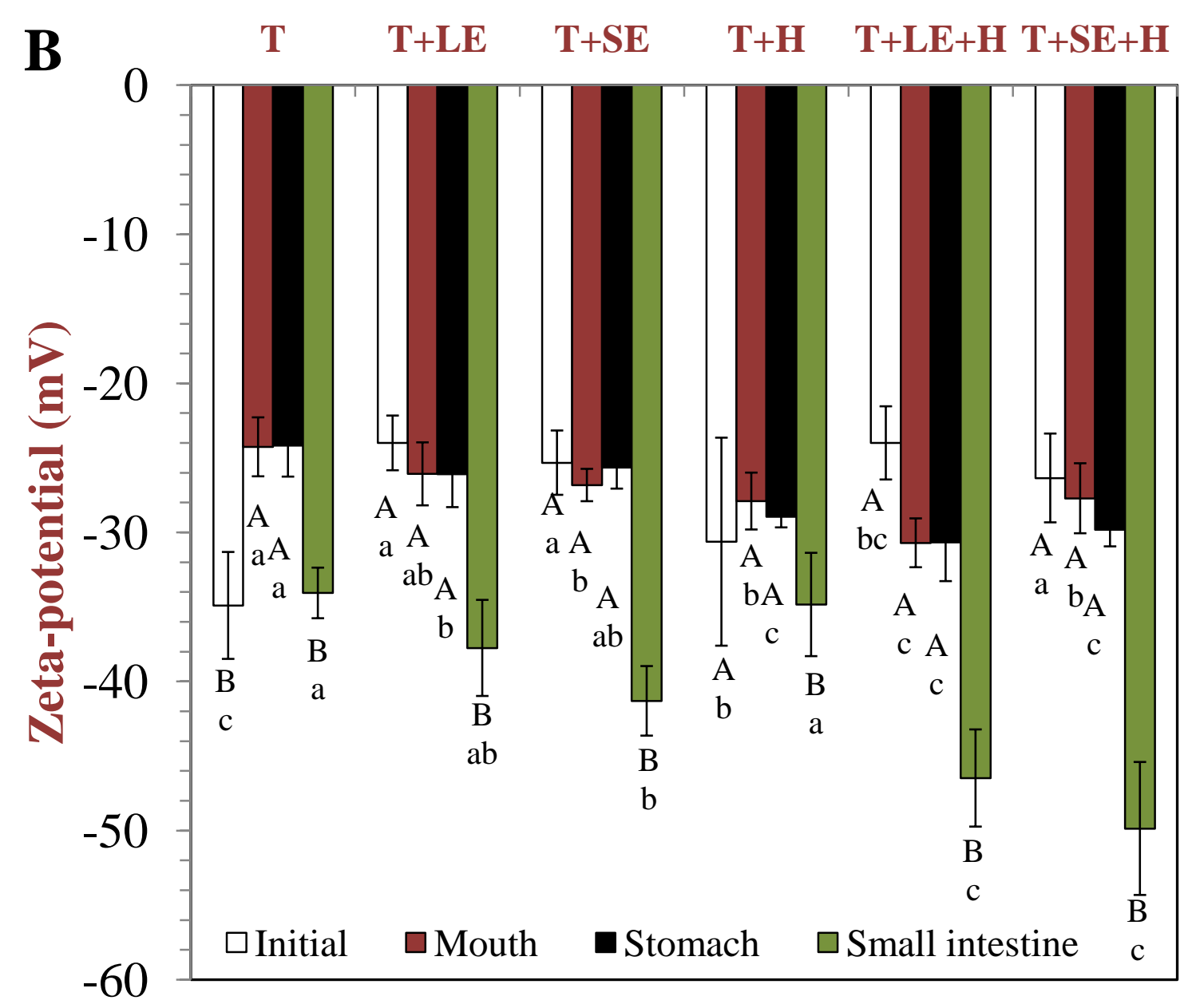

Figure 1 Volume-weighted mean particle size $(\mu \mathrm{m})(\mathrm{A})$ and $\zeta$-potential $(\mathrm{mV})(\mathrm{B})$ of tomato juice $(\mathrm{T})$ mixed with a large emulsion (T+LE) or a small emulsion $(\mathrm{T}+\mathrm{SE})$ and after the application of heat $(90$ $\left.{ }^{\circ} \mathrm{C} 10 \mathrm{~min}\right)(\mathrm{T}+\mathrm{H}, \mathrm{T}+\mathrm{LE}+\mathrm{H}, \mathrm{T}+\mathrm{SE}+\mathrm{H})$ during the in vitro digestion. Different capital letters represent significant differences $(p<0.05)$ between in vitro digestion phases for the same sample. Different lower case letters represent significant differences $(p<0.05)$ between different samples in a given in vitro digestion phase (initial, mouth, stomach or small intestine) 


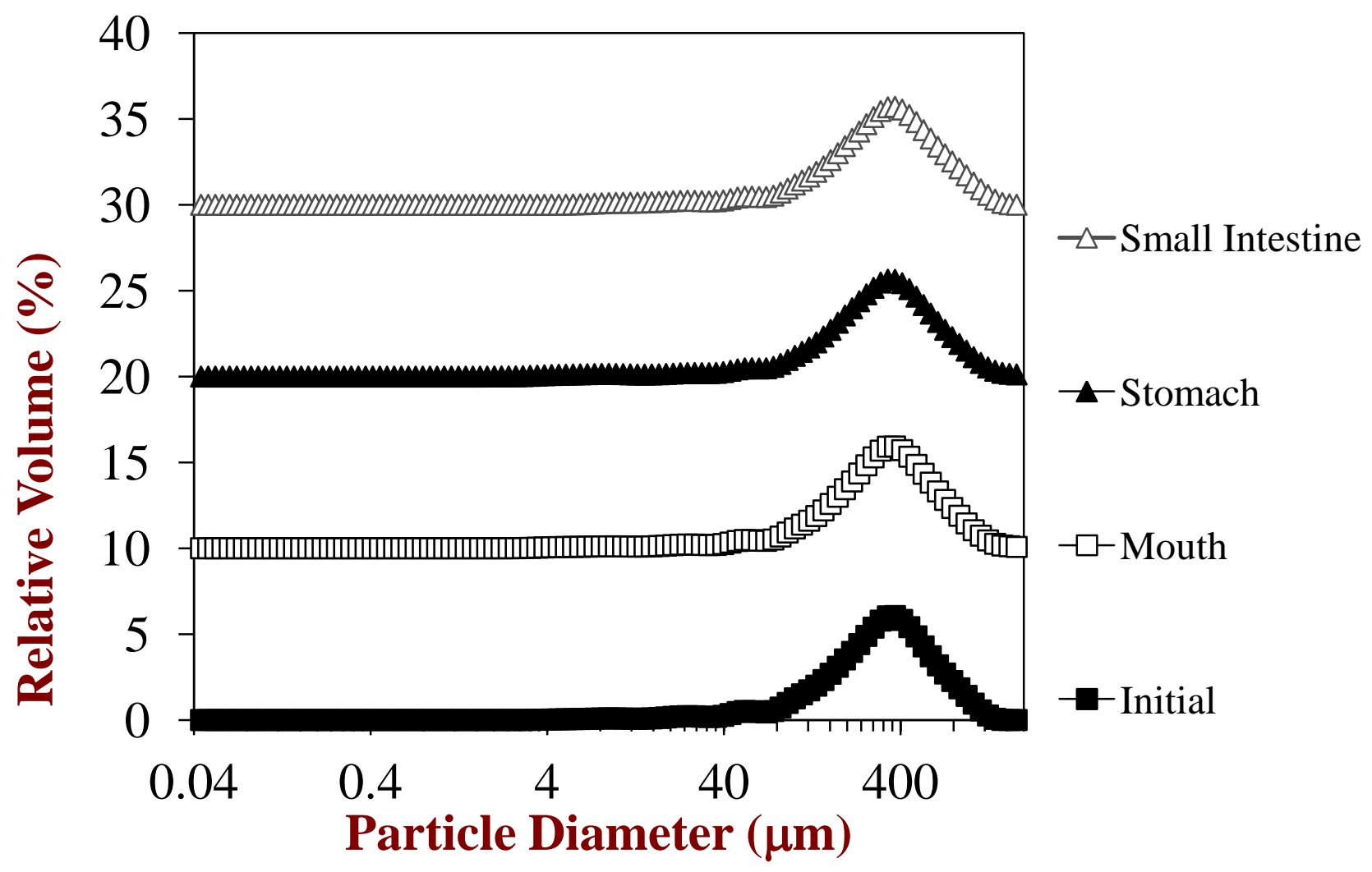

Figure 2 Particle size distribution of raw tomato juice (T) during the in vitro digestion phases (initial, mouth, stomach and small intetsine) 


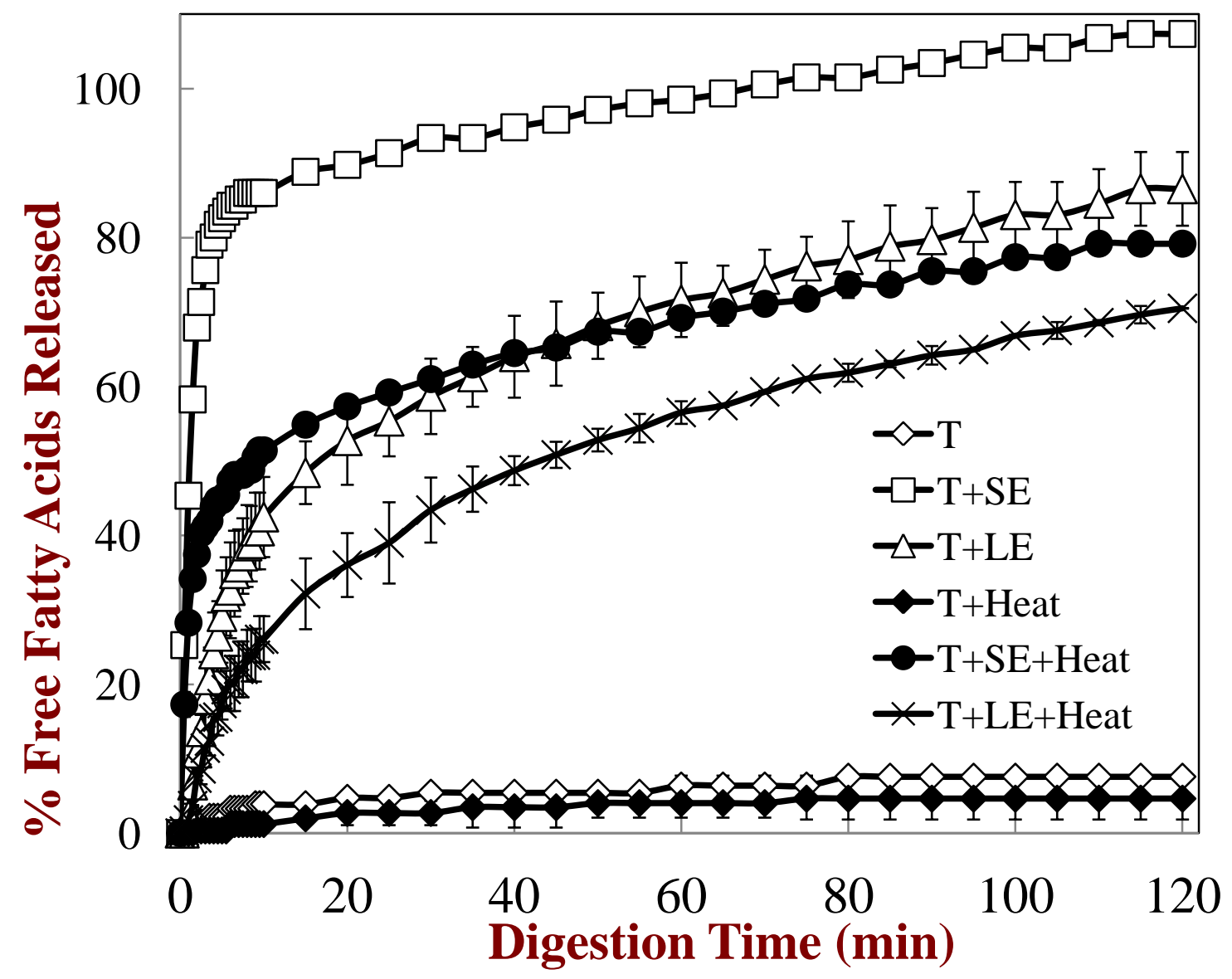

Figure 3. Calculated free fatty acids released (\%) from the tomato juice (T) containing small (SE) or large (LE) excipient emulsions with or without applying heat $\left(90^{\circ} \mathrm{C}\right.$ for $\left.10 \mathrm{~min}\right)$ over time during the course of the in vitro small intestine stage. 

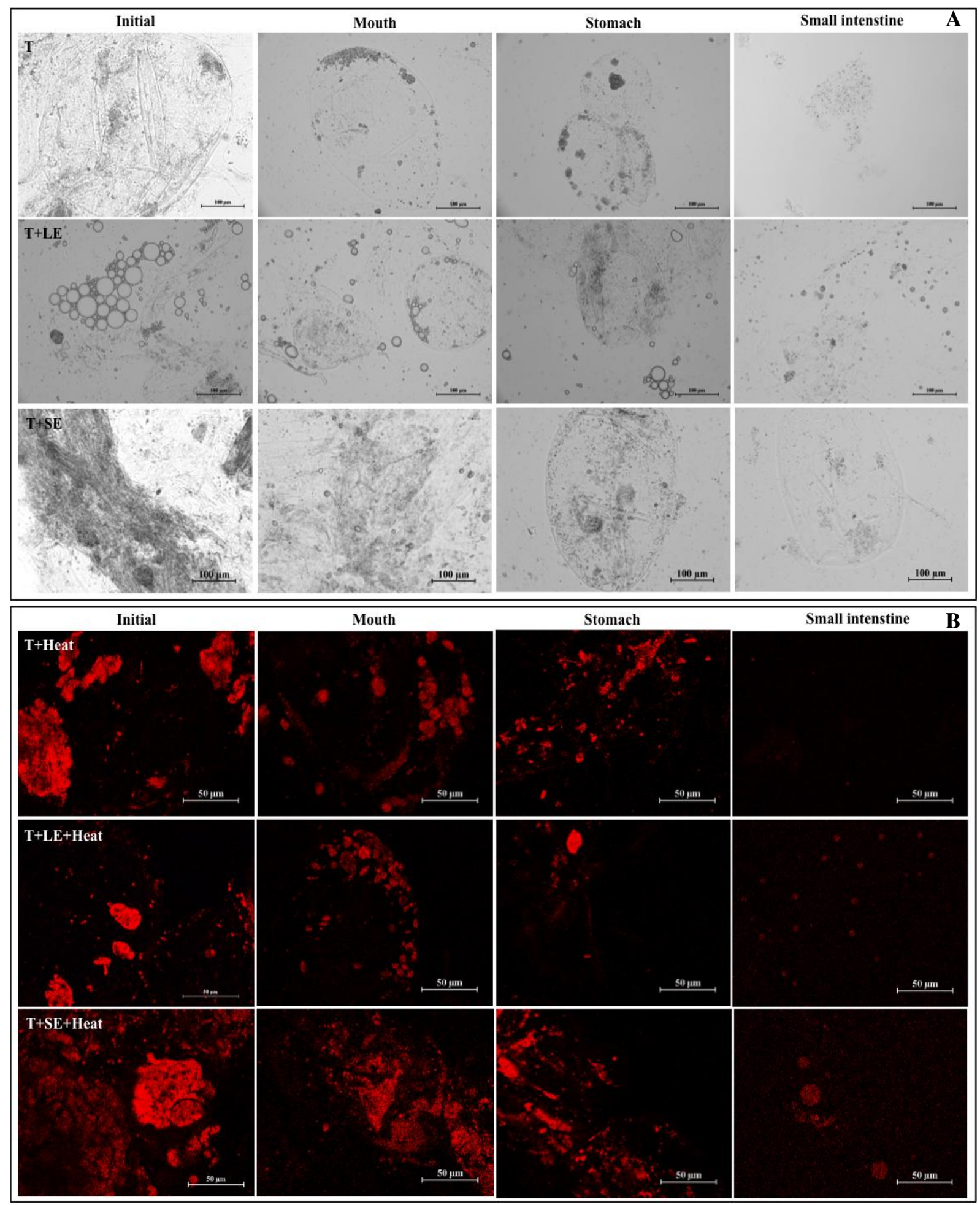

Figure 4 Optical images $(20 \mathrm{X})$ of tomato juice $(\mathrm{T})$, tomato juice with large $(\mathrm{T}+\mathrm{LE})$ or small $(\mathrm{T}+\mathrm{SE})$ excipient emulsion (A) and confocal images $(60 \mathrm{X})$ of heated samples $\left(90^{\circ} \mathrm{C} 10 \mathrm{~min}\right)$ of tomato juice $(\mathrm{T}+\mathrm{Heat})$, tomato juice with large emulsion $(\mathrm{T}+\mathrm{LE}+\mathrm{Heat})$ and tomato juice with small emulsion ( $\mathrm{T}+\mathrm{SE}+\mathrm{Heat}$ ) (B) under simulated gastrointestinal conditions. Scale bar is $100 \mu \mathrm{m}(\mathrm{A})$ and $50 \mu \mathrm{m}$ (B) 

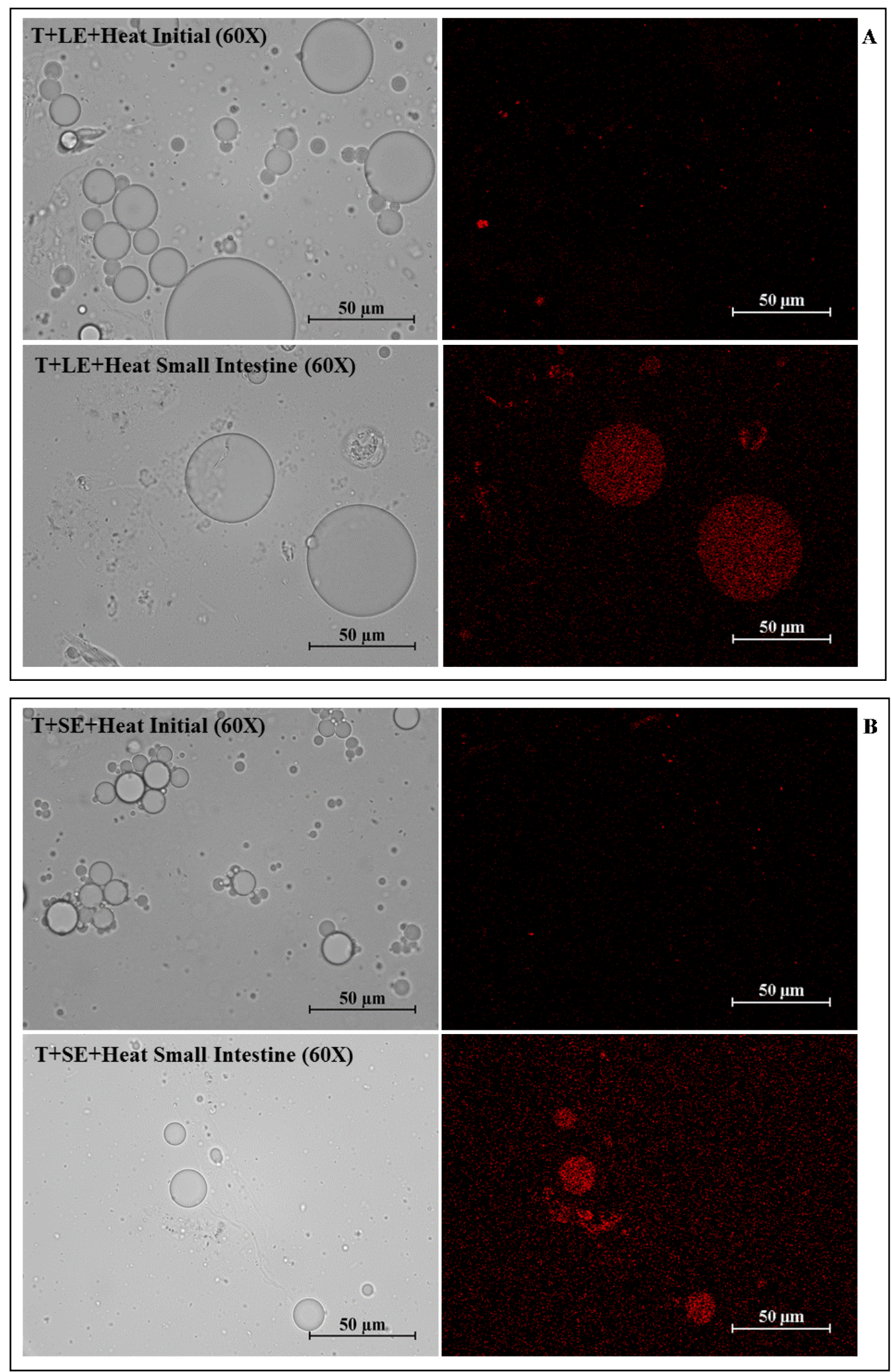

Figure 5 Comparison of optical and confocal images (60X) of tomato juice with large (A) $(\mathrm{T}+\mathrm{LE}+\mathrm{Heat})$ or small (B) (T+SE+Heat) emulsion immediately after heat treatment $\left(90^{\circ} \mathrm{C} 10 \mathrm{~min}\right)$ and after in vitro small intestine phase. Scale bar is $50 \mu \mathrm{m}$. 


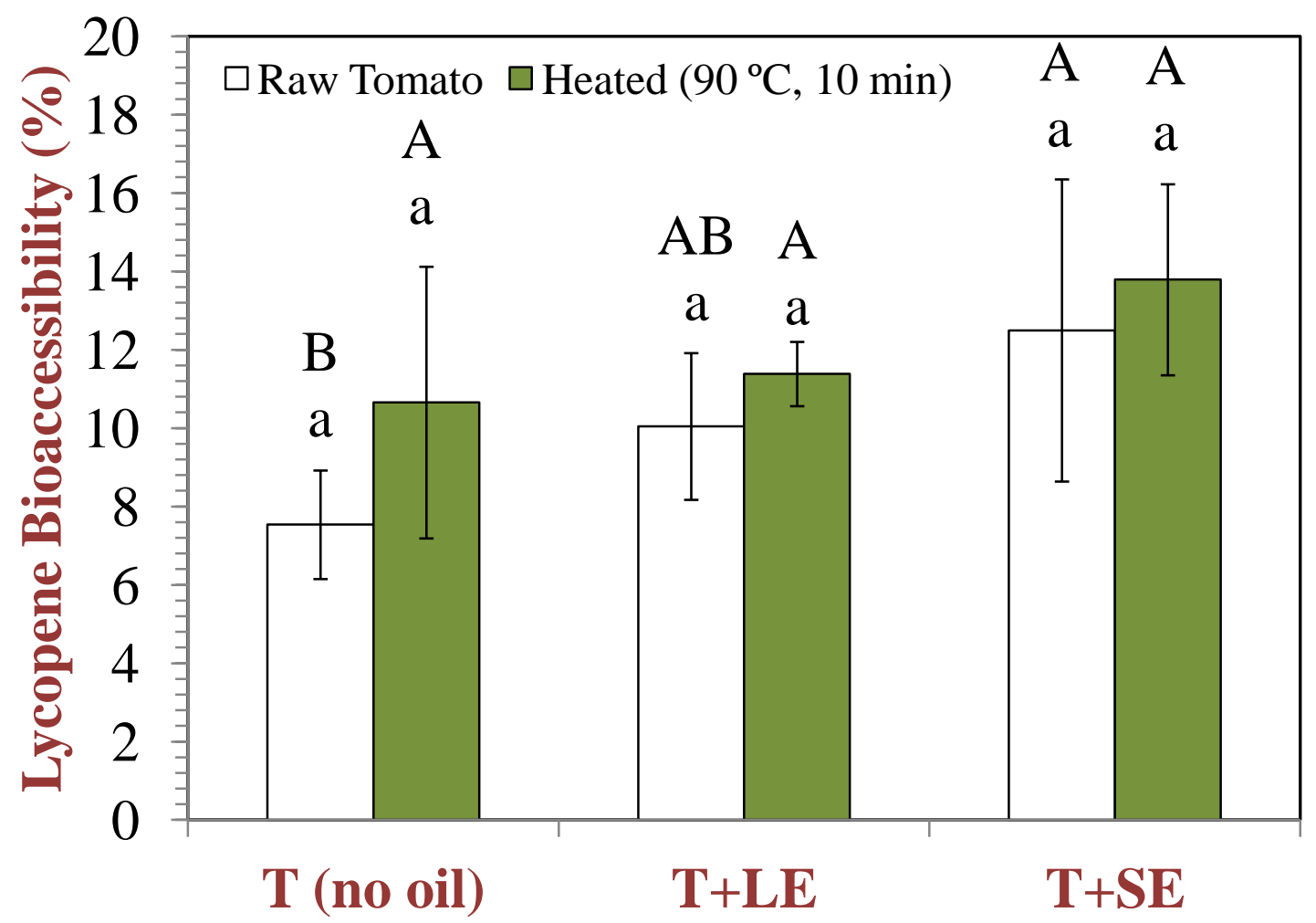

Figure 6 Lycopene bioaccessibility (BA; \%) of tomato juice (T) mixed with large (LE) or small (SE) excipient emulsions with or without a posterior heat treatment $\left(90^{\circ} \mathrm{C} 10 \mathrm{~min}\right)$. Different capital letters represent significant differences $(p<0.05)$ between no addition of oil or adding large or small excipient emulsions. Different lower case letters represent significant differences $(p<0.05)$ between non-treated and heat-treated tomato within the same sample. 